\title{
Experimental Study of Replacement of Cement by SCBA in Concrete
}

\author{
Nidhi Relan ${ }^{1}$, Dr. A K Saxena ${ }^{2}$ \\ ${ }^{1}$ PG Student, Department of Civil Engineering, MITS Gwalior \\ ${ }^{2}$ Deapartment of Civil Engineering, MITS Gwalior
}

\begin{abstract}
Demand and consumption of cement is increasing day by day which has led researchers and scientists to search for locally available alternate binders that can replace cement partially and are ecofriendly and contribute towards waste management. The utilization of industrial and agricultural waste can play a vital role in this direction. In the present study and work the agricultural waste product like sugarcane bagasse ash (SCBA) is used as alternate binding material. This will result in saving in cement production equivalent to the alternative binding material used in concrete. The bagasse ash used for the research work is obtained from Sant Tukaram factory (Pune) which is grinded and sieved through sieve of size 150 micron and passing out fraction is used in concrete as a partial replacement of cement in the ratio of $0 \% 5 \%, 10 \%, 12.5 \%, 15 \%, 20 \%$ and $25 \%$ by weight of the cement. OPC 53 grade cement is used in the study. The effect of replacement of cement by bagasse ash on properties like workability for fresh concrete are tested and for hardened concrete compressive strength at the age of 7 days and 28 days are determined. During preparation of test cubes $0.5 \%$ super plasticizer, Fosroc conplast SP500 (a high range water reducer, based on sulphonated naphthalene polymer) by the weight of cement is also used. The experimental-study reveals that bagasse ash can be replaced up to $12.5 \%$ without affecting the strength of sample of conventional concrete (M35).
\end{abstract}

Keywords: Sugar-cane bagasse ash (SCBA), cement replacement, compressive strength, workability and durability.

\section{Introduction}

Sugar production has emerged as one of the major agro industries all over the world during the last few decades. Sugarcane which is commonly used in sugar production is cultivated in about seventy four countries lying between $40^{\circ} \mathrm{N}$ and $32.5^{\circ} \mathrm{S}$, latitude on the globe encompassing approximately half of the globe (Agboire et al., 2002). [3] In India sugar production is undertaken practically throughout the country and there are well-established large scale factories in 18 out of 29 States. According to the reports for the last crushing season, there were 338 factories in operation which crushed about 60 million tonnes of cane, producing 6.1 million tonnes of sugar and 2.5 million tonnes of molasses. Average bagasse production is about 30 percent of the sugarcane crushed and about 90 percent of bagasse produced is used as fuel. After controlled burning of bagasse ,the ash obtained is known as bagasse ash .Now a days, bagasse is also being used in the manufacturing of pulp and paper products. Previous researches have shown that for each 10 tons of sugarcane crushed; a sugar factory produces nearly 3 tons of wet bagasse which is a waste product of the sugar cane industry. It is the cellular and fibrous waste product after the extraction of the sugar juice from sugar cane. Bagasse ash is a residue obtained from the burning of bagasse in sugar producing factories. A good solution to the problem of recycling of sugarcane residues would be by burning them in a controlled environment and use the ashes (waste) for more noble means (Ghavami et al., 1999).[3] SCBA constitutes an environmental nuisance as they form refuse heaps in areas when they are disposed off in low lying areas. Western Maharashtra is having maximum number of sugar factories and these factories are now facing disposal problem of large quantity bagasse. The effective utilization of these waste products is a challenging task for a researcher through economical and environmental friendly way.
The use of SCBA in concrete reduces the heat of hydration and increases the life of structure [2]. The reasons behind using this material in concrete is that it contains large percentage of amorphous silica and alumina, which is responsible for secondary hydration, when SCBA comes in contact with hydration products of cement and produces higher strength as compared to conventional concrete due to formation of additional C-S-H gel utilizing harmful lime produced during hydration. It has been found by various researches that Bagasse ash is a valuable pozzolanic material similar to that of slag, fly ash and ground granulated blast furnace ash (GGBS). Moreover usage of bagasse ash in concrete helps in reduction of dead weight thereby producing light weight structures.

\section{Methodology of Making Bagasse Concrete}

After controlled burning of bagasse, the ash obtained (SCBA) is Grinded and sieved through $150 \mu$ size sieve which provides fine bagasse ash .SCBA so obtained was characterized for its physical and chemical properties in pollution control board lab in pune. On the basis of characteristics of SCBA, suitability of SCBA to be used for replacement of cement in concrete production is accessed.

For experimentation M-35 controlled concrete using locally available building materials (aggregates and sand) and OPC53 grade cement is used with suitable dose of admixture (Fosroc conplast SP500). Mix designing of M-35 controlled concrete is done and results are validated by casting 12 cube samples $(150 \mathrm{~cm} \times 150 \mathrm{~cm} \times 150 \mathrm{~cm})$ and subsequently testing it for compressive strength after 7 days and 28 days .Slump value is also maintained at $75 \mathrm{~mm}$ (average) values as that of controlled concrete. 


\section{International Journal of Science and Research (IJSR) \\ ISSN (Online): 2319-7064 \\ Index Copernicus Value (2013): 6.14 | Impact Factor (2014): 5.611}

After the above work cement is replaced by SCBA in the ratio of $5 \%, 10 \%, 15 \%, 20 \%$ and $25 \%$ in the concrete keeping same workability of concrete. Twelve samples of each SCBA replacements are tested for 7 days and 28 days compressive strength .On the basis of experimentation it is observed that about $12.5 \%$ replacement of cement by SCBA for M-35 concrete can be done without changing the strength of concrete

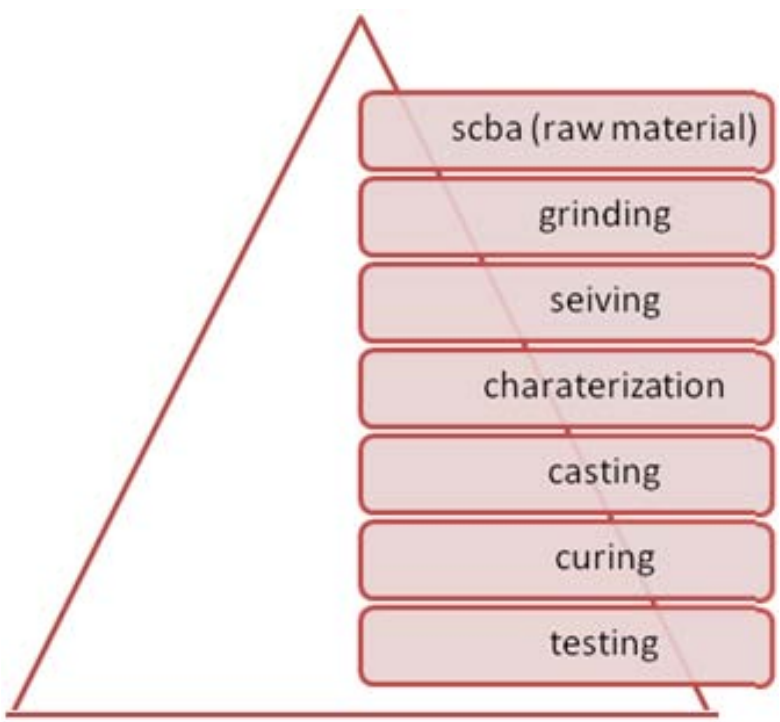

Figure 1: Methodology of using bagasse ash

\section{Materials and Methods}

\subsection{Cement}

In this experimental work Ordinary Portland cement (Grade 53) conforming to IS $12269-1987$ in all trial mixes is used. The physical properties of the cement obtained on conducting appropriate tests conforming to process laid down in IS: 269/4831 has been performed. The results are mentioned in table 1 shown below

Table 1: Physical properties of cement

\begin{tabular}{|c|c|c|}
\hline S. No & Property of cement & value \\
\hline 1 & Fineness of cement $\left(\mathrm{m}^{2} / \mathrm{kg}\right)$ & 320 \\
\hline 2 & Specific gravity of cement & 3.15 \\
\hline 3 & Grade of cement $(\mathrm{OPC})$ & 53 grade $0 \mathrm{pc}$ \\
\hline 4 & Standard consistency of cement & $35 \%$ \\
\hline 5 & Initial setting time & $90 \mathrm{mins}$ \\
\hline 6 & Final setting time & $265 \mathrm{mins}$ \\
\hline 7 & Compressive strength (MPA)(28 days) & 61.00 \\
\hline
\end{tabular}

\subsection{Aggregate}

In this study stone dust passing through $4.75 \mathrm{~mm}$ sieve conforming to Zone II as per IS: $383-1970$ is used as fine aggregate. The fine aggregate is free from clay, silt and organic impurities. Crushed angular/cubical coarse aggregates of locally available rock is used in the study, 20 $\mathrm{mm}$ and $10 \mathrm{~mm}$ MSA coarse aggregate is sieved and their gradation is done .To satisfy the combined gradation of Coarse aggregates IS $383-1970$ it is proposed that the proportion of 53:47 of $20 \mathrm{~mm} \& 10 \mathrm{~mm}$ aggregates produces the best gradation as per IS: 383 .
Table 2: Properties of Coarse Aggregate

\begin{tabular}{|c|c|c|c|}
\hline Physical test & $\begin{array}{c}\text { Coarse } \\
\text { aggregate } \\
(20 \mathrm{~mm})\end{array}$ & $\begin{array}{c}\text { Coarse } \\
\text { aggregate } \\
(10 \mathrm{~mm})\end{array}$ & $\begin{array}{c}\text { Fine } \\
\text { aggregate }\end{array}$ \\
\hline Specific gravity & 2.62 & 2.62 & 2.59 \\
\hline Fineness modulus & 2.96 & 3.82 & 2.36 \\
\hline Bulk density $\left(\mathrm{kg} / \mathrm{m}^{3}\right)$ & 1.8 & 1.67 & 1.58 \\
\hline
\end{tabular}

3.3 Water: Fresh potable drinking water of $\mathrm{Ph}$ value (6.57.2) free from organic impurities is being used which is available in college campus.

3.4 Superplastisizer: Water reducing admixture brand conplast SP500 from Fosroc with a dose of $0.5 \%$ by weight of Cement is used.

3.5 Bagasse ash: Bagasse ash was obtained from Shri Sant Tukaram factory in the near vicinity. Physical and chemical properties of the bagasse ash are mentioned in Table 3A and 3B.

Table 3 (A): Chemical Properties of bagasse ash

\begin{tabular}{|c|c|}
\hline Chemical components & \% Weight \\
\hline $\mathrm{SiO}_{2}$ & 80.12 \\
\hline $\mathrm{Al}_{2} \mathrm{O}_{3}$ & 8.51 \\
\hline $\mathrm{Fe}_{2} \mathrm{O}_{3}$ & 3.61 \\
\hline $\mathrm{CA}_{\mathrm{O}}$ & 2.06 \\
\hline $\mathrm{Na}_{2} \mathrm{O}$ & 0.14 \\
\hline $\mathrm{K}_{2} \mathrm{O}$ & 3.37 \\
\hline $\mathrm{MgO}$ & 0.11 \\
\hline $\mathrm{TiO}_{2}$ & 0.50 \\
\hline $\mathrm{BaO}$ & 0.16 \\
\hline $\mathrm{P}_{2} \mathrm{O}_{5}$ & 1.00 \\
\hline & 0.42 \\
\hline
\end{tabular}

Table 3(B): Physical properties of bagasse ash

\begin{tabular}{|c|c|}
\hline Properties & Bagasse ash \\
\hline Specific gravity & 2.06 \\
\hline Fineness modulus & 2.12 \\
\hline Bulk density & $1408 \mathrm{~kg} / \mathrm{m}^{3}$ \\
\hline
\end{tabular}

\subsection{Slump Test}

Workability of concrete is a composite property. Workability for the fresh concrete was tested by slump cone test method. The following are the results of fresh concrete using slump cone test for various percentage of replacement of cement by SCBA.

Table 4: Showing adjustment of w/c ratio for getting $75 \mathrm{~mm}$ slump value

\begin{tabular}{|c|c|c|c|}
\hline SR. & $\%$ & WATER/ CEMENT & SLUMP \\
NO & SCBA & RATIO & VALUE \\
\hline 1. & $0 \%$ & 0.43 & $70-80 \mathrm{~mm}$ \\
\hline 2. & $5 \%$ & 0.42 & $72-80 \mathrm{~mm}$ \\
\hline 3. & $10 \%$ & 0.41 & $70-81 \mathrm{~mm}$ \\
\hline 4. & $15 \%$ & 0.40 & $68-78 \mathrm{~mm}$ \\
\hline 5. & $20 \%$ & 0.39 & $69-81 \mathrm{~mm}$ \\
\hline 6 & $25 \%$ & 0.38 & $70-83 \mathrm{~mm}$ \\
\hline
\end{tabular}

Above data clearly revealed that the addition of bagasse ash in concrete produces higher slump value which implies that increasing of percentage of bagasse workability increases. Therefore to keep same workability, water cement ratio was 


\section{International Journal of Science and Research (IJSR) \\ ISSN (Online): 2319-7064 \\ Index Copernicus Value (2013): 6.14 | Impact Factor (2014): 5.611}

reduced for each replacement of cement by SCBA. The modified value of $\mathrm{w} / \mathrm{c}$ ratio shown in above table

\section{Mix Proportioning of Bagasse Ash Concrete}

\subsection{Experimental Work}

In present study initially, five replacements of cement i.e. $5 \%, \quad 10 \%, \quad 15 \%, \quad 20 \%, \quad 25 \%$ designated $\mathrm{CC}$,
CBA1,CBA2,CBA3,CBA4,CBA5 respectively with bagasse ash (BA) are studied, where as the total binder content remains the same ( i.e cement + SCBA value)

The mix proportions considered for each replacement of cement by replacing method with SCBA are presented in table 5

Table 5: Mix proportioning of bagasse concrete

\begin{tabular}{|l|l|l|l|l|l|l|}
\hline \multicolumn{1}{|c|}{ Materials/percentage } & $0 \%(c c)$ & $5 \%(C B A 1)$ & $10 \%(C B A 2)$ & $15 \%(C B A 3)$ & $20 \%(C B A 4)$ & $25 \%(C B A 5)$ \\
\hline CEMENT(KG) & 11.87 & 11.276 & 10.68 & 10.118 & 9.426 & 8.903 \\
\hline SCBA(KG) & 0 & .5935 & 1.187 & 1.752 & 2.374 & 2.967 \\
\hline WATER(ml) & 5.104 & 4.7359 & 4.3788 & 4.0472 & 3.676 & 3.383 \\
\hline COURSE AGG(KG)20MM & 18.315 & 18.315 & 18.315 & 18.315 & 18.315 & 18.315 \\
\hline COURSE AGG(KG)10 MM & 16.143 & 16.14 & 16.14 & 16.14 & 16.14 & 16.14 \\
\hline FINE AGG(KG) & 18.843 & 18.843 & 18.843 & 18.843 & 18.843 & 18.843 \\
\hline FOSROC 500 & $59.3 \mathrm{GM}$ & $56.38 \mathrm{GM}$ & $53.40 \mathrm{GM}$ & $50.59 \mathrm{GM}$ & $47.13 \mathrm{GM}$ & $44.515 \mathrm{GM}$ \\
\hline
\end{tabular}

\subsection{Compressive strength}

The compressive test was conducted using a $2000 \mathrm{kN}$ capacity compression testing machine. This test was conducted as per the relevant Indian Standard specifications. Two trials (coarse trial and fine trial) were conducted to find compressive strength of concrete. The optimum quantity of SCBA replacement expected to lie between $10-15 \%$. For getting more accurate values of replacements, three trials with $10 \%, 12.5 \%, 15 \%$ replacement are tried which is called as fine trial, the results of fine trial are as follows.

Table 6A: Coarse trial showing compressive strength 7/28daysfor various replacements of cement by SCBA for M

\begin{tabular}{|c|c|c|c|}
\hline \multicolumn{4}{|c}{35 grade } \\
SR. & $\begin{array}{c}\% \text { REPLACEMENT } \\
\text { OF SCBA }\end{array}$ & $\begin{array}{c}* 7 \text { DAYS } \\
\text { STRENGTH }\end{array}$ & $\begin{array}{c}* 28 \text { DAYS } \\
\text { STRENGTH }\end{array}$ \\
\hline 1 & $0 \%$ & 30.67 & 43.44 \\
\hline 2 & $5 \%$ & 35.48 & 46.6 \\
\hline 3 & $10 \%$ & 37.18 & 47.62 \\
\hline 4 & $15 \%$ & 30.10 & 40.40 \\
\hline 5 & $20 \%$ & 26.44 & 34 \\
\hline 6 & $25 \%$ & 25.80 & 33 \\
\hline
\end{tabular}

*Strength is average of 3 cube samples

Table 6B: Fine trial showing compressive strength 7/28days for various replacements of cement by SCBA for M 35 grade

\begin{tabular}{|c|c|c|c|}
\hline SR.NO & $\begin{array}{c}\% \\
\text { REPLACEMENT } \\
\text { OF SCBA }\end{array}$ & $\begin{array}{c}7 \text { DAYS } \\
\text { STRENGTH }\end{array}$ & $\begin{array}{c}28 \text { DAYS } \\
\text { STRENGTH }\end{array}$ \\
\hline 1 & $10 \%$ & 33.67 & 45.64 \\
\hline 2 & $12.5 \%$ & 37.48 & 47.22 \\
\hline 3 & $15 \%$ & 30.20 & 40.08 \\
\hline
\end{tabular}

As per above mentioned test results it is observed that the compressive strength of cube decreases beyond $10 \%$ replacement of cement by SCBA. To determine optimum value of SCBA replacement fine trials with $10 \%, 12.5 \%, 15 \%$ SCBA replacement are tried and results are mentioned in table $6 \mathrm{~B}$
Observed values of compressive strength of concrete cubes for various \% replacement of cement by SCBA are also shown by graph for at a glance observation (fig. 2A and 2B)

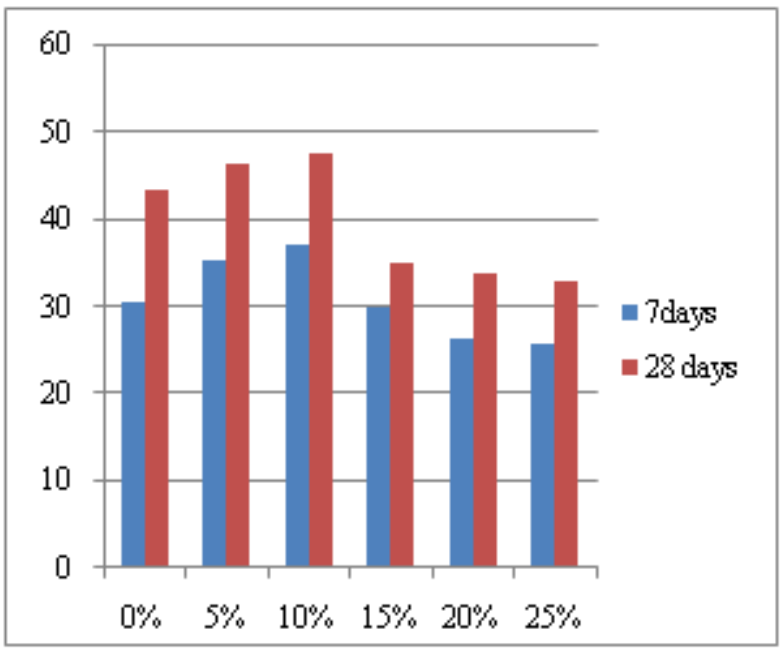

Figgure 2A: Coarse trial showing Compressive strength for cube

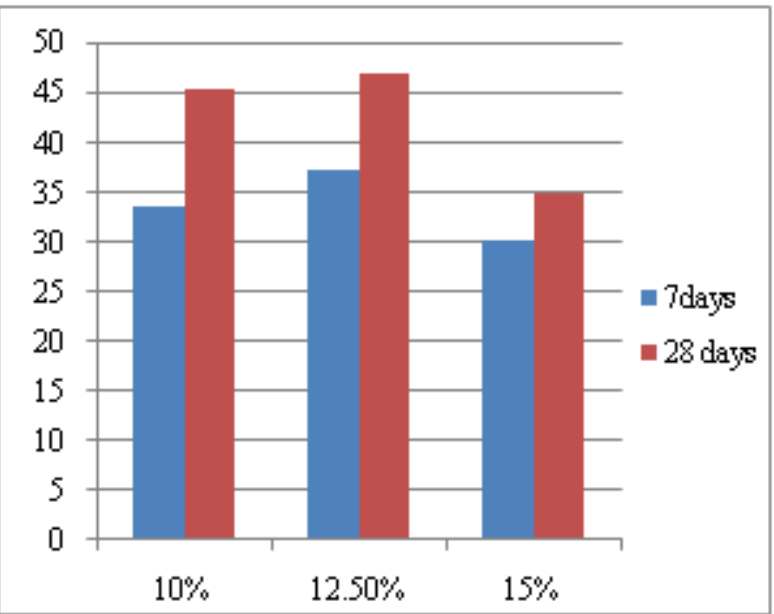

Figure 2B: Fine trial showing compressive strength for cube 


\section{Conclusion}

1) From the study conducted, it is concluded that workability of concrete increases by increasing the percentage of replacement of SCBA in concrete.

2) It is concluded that finely grounded SCBA can be succesfully replaced by cement and is responsible for higher compressive strengths than normal concrete (keeping quantity of cement constant)

3) It is concluded that the cement could be advantageously replaced with SCBA up to a maximum limit of $12.5 \%$.for M35 concrete. The study reveals that the compressive strength increased up to $10 \%$ replacement whereas beyond $15 \%$ replacement the strength was found to be decreasing. Therefore it is possible to use bagasse (SCBA) as cement replacement material to improve quality control and reduction of cost

4) Like other pozolanic material i.e fly ash ,GGBS \& slag, bagasse ash is also a valuable pozolonic material so it can definitely be used as a partial replacement of cement. This could reduce the ecological complications and minimize the requirement of land fill area to dispose SCBA.

5) Optimum Percentages of replacement of cement by SCBA will vary from different grade of concrete which is a further scope of study.

6) To keep same workability water cement ratio needs to be reduced for each replacement of cement by SCBA.

\section{References}

[1] S.Dharanidharan*, L.Rajkumar, B.Karthick "An experimental study on mechanical properties of concrete by using sugarcane bagasse ash" International journal of engineering sciences \& research Technology Vol no (3): March, 2015] ISSN: 2277-9655 Scientific Journal Impact Factor: 3.449 (ISRA), Impact Factor: 2.114

[2] K Meeravali, ${ }^{2}$ K V G D Balaji, ${ }^{3}$ T. Santhosh Kumar ${ }^{1}$ PG Student, ${ }^{2}$ Professor, ${ }^{3}$ Assistant Professor, Department of Civil Engineering, Gitam University, India "partial replacement of cement in concrete with sugar cane bagasse ash-behaviour in HCL solution" International Journal of Advance Research In Science And Engineering IJARSE, Vol. No.3, Issue No.7, July 2014 ISSN-2319-8354(E) 368

[3] ${ }^{1}$. T. S. Abdulkadir, ${ }^{2}$. D. O. Oyejobi, ${ }^{3}$ a. A. Lawal 1-3. Department of Civil Engineering, University of Ilorin, Ilorin, NIGERIA“" Evaluation of sugarcane bagasse ash as a replacement for cement in concrete works" ACTA Technica Corviniensis ,Fascicule 3 (julyseptember) ISSN 2067- 3809

[4] M S SHETTY 